\title{
GEOTHERMAL ENERGY AS A RENEWABLE ENERGY SOURCE IN REPUBLIC OF SRPSKA
}

DOI: http://dx.doi.org/10.18509/GBP.2015.10

UDC: 620.97:553.78(497.6)

\author{
Dr Vesna Rajčević, Dr Čedomir Crnogorac, PhD
}

Faculty of Sciences, University of Banja Luka

\begin{abstract}
The process of exchange of energy between the natural environment and human population has been a historical category determined by the development of production forces and relationships. An appropriate structure of exchange of matter in the naturesociety-nature cycle has been applied in order for all the material and cultural needs of the society to be satisfied. With the development of human population there has been a specific social link formed in the chain of general exchange of matter on Earth, apart from the biological one. One of the more important economic-geographic aspects of the environment is energetics, that is, the technique of application and exploitation of different forms of energy. Energy and fuels present a global issue today, the main aspects of which are energy resources, their consumption, the security of energy infrastructure and energy systems. When the availability and exploitation of certain energy resources in modern world are concerned, the assessment of the influence of certain fuels on the environment plays a key role in achieving these goals. For that reason the world today witnesses an increased interest in renewable energy resources: geothermal energy, wind energy, solar energy, biomass, waste and hydro power. This process has been incited by the level of exhaustion of conventional fuels - fossil fuels, as well as by the impact on the environment of their intense exploitation. Based on the research conducted so far on the Republic of Srpska geospace, it is evident that renewable energy resources are not sufficiently researched into and not been paid too much attention in the past period. There are numerous reasons for this state of affairs: the recent civil war in Bosnia and Herzegovina, a poor pace of restoration of the devastated industrial facilities, lack of domestic and foreign funds for fundamental research into the field, limited budgetary funds, scarcity of qualified personnel etc. The areas of Republic of Srpska interesting in this respect are the vicinity of the town of Višegrad, the western part of the city of Sarajevo area, the area along the route of the towns of Doboj, Maglaj and Teslic respectively, the area encompassing the towns of Prijedor and Novi Grad and the town of Zvornik - the village of Janja area. However, in order to start using geothermal resources in Republic of Srpska, it is necessary to define the basic approach through the Environmental Impact Study, which implies the harmonization of development goals, that is, a viable development. It also implies the harmonization of the requests for optimal use of space, which means the implementation of the GEMS system (Global Environment Monitoring System). The methods used in the paper cover the analysis and synthesis method, statistical method, the method of assessment and valorization of the environment and method of the direct monitoring of the environment.
\end{abstract}

Key words: renewable energy resources, geothermal energy, the environment, geospace of Republic of Srpska. 


\section{INTRODUCTION}

The subject matter of this paper is defined by the need for affirming the renewable energy sources and their more intense utilisation in Republic of Srpska and Bosnia and Herzegovina. The fact is that the unstable fossil fuels market, monopolies by some manufacturers and distributors, uncontrolled increase in price of some types of fossil fuels as well as their increasingly evident role in environmental pollution require an effective response.

Energy is the base of economic growth of every geographical area, and hence its production and consumption are constantly increasing. Energetics, a modern technical field, is at the same time a technical, physical and economic science (both theoretical and applied) on energy and sources of energy. Basically, its aim is to find and use energy sources for technical, economic and other purposes.

The history of human society's material culture is closely connected with the invention and utilisation of different forms of energy. The overall development of production forces largely depends on the status of energy supply.

When analysing the scope of matter interchange between society and natural environment, the resource cycles ought to be fully comprehended. The resource cycles are considered to be changes of natural characteristics and relocation of certain natural elements or groups of elements in the process of their utilisation by the humankind. The natural resources from that frame are linked within the artificial cycle of matter and energy on Earth.

Not only do the resource cycles include the phases of matter interchange in production but also other phases of matter interchange between nature and society. Moreover, it is necessary to mention that the resource cycles also include the renewable natural resources such as soil, vegetation, water bodies etc. These resources are closely connected with the biological link of circulation of matter.

Of all foregoing cycles, the most significant one is the energy resource cycle - an energy cycle closely connected with the mater-energy structure of the natural environment. The energy resource cycle and energy cycle is the general initiator of material production and, consequently, all human activities in the natural environment. Besides all types of energy in the mantle (the solar and cosmic, tectonic, magmatic, chemical energy of oxidation processes, biological synthesis, photosynthesis and chemical synthesis) acting by the laws of natural and cosmic processes and forces, and measured by geological intervals from 4.5 billion years ago, there is also the energy of world industry, which particularly came to the fore in the $20^{\text {th }}$ century. This energy is measured on the historical scale and has the trend of doubling every 15 years [3]. According to the global data, about 9 billion tons of optimal heat burns every year ( $1 \mathrm{~kg}$ of optimal heat generates about 7,000 kcal of heat). The global need for basic energy resources, counted as the optimal heat, increased from 950 million tons in 1900 to 1.6 billion tons in 1913 and 6.3 billion tons in 1967. This information shows that the need for energy resources in the first two thirds of the $20^{\text {th }}$ century increased by 6.6 times. It is reckoned that the need for energy in the last third of the $20^{\text {th }}$ century additionally increased by about three times.

The increasing need for energy and simultaneous decrease of the basic energy resources lead to the use of energy raw materials of a low level of energy efficiency. For comparison, 35\% energy efficiency coals were used in 1967, whereas nowadays the coals in use are of only $20 \%$ energy efficiency. The oil energy efficiency rate is quite similar. For example, in 1938 the oil pollution rate was only 22\%, while in 1967 it was 54\%. 
Protection of environment and the complex mantle from adverse effects of the energy resource cycle in the next period will most probably go in these two basic directions: searching for new modern clean energy sources and enhancing the existing sources accompanied with measures of rational consumption. Scope of scientific and research work must be introduced as a rule into development of energy cycle. Preservation and improvement of characteristics of the existing geographical environment must primarily be taken into account in solving numerous technical and technological issues. The use of renewable energy sources and maximal decrease in the use of fossil fuels is almost an imperative.

\section{DISCUSSION}

The increase in the number of human population accompanied by increase in developed countries' energy needs on one hand, and limited reserves of natural/fossil resources on the other have brought the issue of energetics in the focus of attention. In the era of dependence on available energy sources, the energy crisis would mean the collapse of a number of infrastructural systems, while the impact on the global economy as well as the economies of a large number of countries would be disastrous. For those reasons, more and more attention is paid to exploration of energy sources, methods of their improvement and substitution with new ones as well as energy saving and raising global awareness of the state of energy resources.

Strategic goals of developed countries in energy sector are increasingly turning towards providing sufficient and safe reserves, primarily their own energy with minimal costs of production, transformation and distribution. The exhaustion of conventional energy sources, fossil fuels, as well as the impact of their intensive exploitation on environment, has increased the interest of many countries in renewable energy sources and possibility of their use.

On one hand, the inexhaustibility of renewable energy sources is seen as their advantage, while on the other hand they are unreliable in terms of energy efficiency, and also periodical in availability and virtually unacceptable for storage. However, the fact is that authorised bodies in the international community are more and more emphasising/insisting on increased use of renewable energy sources like: hydro power, solar energy, wind energy, tidal and ocean wave energy and, especially, geothermal energy. Nevertheless, it must not be forgotten that the aforesaid energy resources are those which depend on a number of environmental and geographical position factors. Therefore, they can be locally available or unavailable as natural resources. Regarding the use of different technologies and degree of economic development, the existing resources can be used to a different extent. The previous degree of use of renewable energy resources has still been symbolic because, besides significant investment costs which these resources require, the capacity and limitations to their utilisation have still not been sufficiently investigated. Technologies of the use of renewable energy resources are, as a general rule, more expensive in relation to technologies for using fossil fuels (the so-called conventional technologies) or large-scale plants (e.g. large hydro power plants). Talking about Republic of Srpska (RS), it can be concluded that renewable energy sources have still not been sufficiently explored. Generally, they are an issue having been insufficiently addressed in the recent period. The lack of qualified professionals and a sceptical attitude to possibilities of a justified exploitation of renewable energy sources have resulted in a poor interest of local authorities and, accordingly, low level of their utilisation. With regard to renewable energy sources in Republic of Srpska, we can say 
that there are considerable hydro power resources and insufficiently explored wind energy, solar energy, biomass energy and geothermal energy. A specific continental position of Republic of Srpska is the reason for non-existence of resources like tidal and wave energy.

\section{SOLAR ENERGY}

Solar energy is generated through the process of thermonuclear fusion of hydrogen and helium nuclei, by which the lost mass is converted into energy radiating into surrounding space. Solar energy also has an indirect impact on other forms of renewable energy. The impact of the sun on water powers, wind, biomass, tide and ebb tide is well-known. The use of solar energy is limited to the local circumstances such as the duration of insolation, number of sunny days during the year, state of atmosphere in terms of appearance of fog and the level of air pollution, level of technical culture and education of population etc $[2]$.

Regarding the level of insolation in Republic of Srpska, it is up to $1.25 \mathrm{MWh} / \mathrm{m}^{2}$ on horizontal surfaces in the northern parts, and up to $1.55 \mathrm{MWh} / \mathrm{m}^{2}$ in the southern parts around the town of Trebinje. The use of this form of renewable energy in Republic of Srpska is nowadays limited to individual solar collectors in a small number of households as well as some large structures, and to the use of small photovoltaic systems. A promising application of renewable energy is expected in the form of solar collectors for hot water preparation and photovoltaic systems for production of electricity. Relatively high prices of solar collector installation represent a limiting factor of potential use in the future, requiring co-financing especially in buildings where the use of heating oil will be reduced.

\section{WIND ENERGY}

The significance of wind energy as a form of renewable energy lies in its availability in Republic of Srpska despite the fact that it is not used for power production nowadays. A potential use of wind energy would be to produce mechanical energy by using the energy of air mass movement, which would in turn be converted into electrical energy. The advantages of exploring this energy source are quantities of energy obtained in a totally clean way, while power production plants occupy small areas of land.

The characteristics of terrain and frequent gale-force winds nominate the southern part of Republic of Srpska (Eastern Herzegovina) as the most perspective area for construction of wind farms. The RS Energy Sector Development Strategy by 2030 points out a theoretical existence of resources for construction of these plants in even 13 locations from Kalinovik to Trebinje. Having in mind high investments required for construction of wind farms and preceding research, the realisation of development projects will largely depend on foreign investments.

\section{HYDRO POWER}

Hydro power is a conventional but also renewable energy source characterised by a long tradition of use for production of mechanical i.e. electrical energy. It depends on a characteristic local hydro power potential based on which Republic of Srpska is counted as a water-rich area. The technically available river potential in Republic of Srpska is $13505 \mathrm{GWh} /$ year, which accounts for $45-55 \%$ of overall electricity consumption in 
Republic of Srpska[4] $]^{3}$ Substantial investments are necessary for maintenance of the existing HPPs in order to increase the reliability of exploitation. Bearing in mind a constant increase in price of energy-generating products in the global market, electricity is becoming one of most significant export products. Therefore, the hydro power resources available in Republic of Srpska could provide a considerable economic benefit in the time to come, which could in turn be used for new development projects.

\section{BIOMASS ENERGY}

Biomass is the oldest energy source used by the humans and represents a universal term for numerous, various products of herbal and animal world, and can be divided into energy crops and waste. Biomass as a renewable energy source includes: firewood, branches and wooden waste from forestry, sawdust, bark and wooden remains from wood processing industry as well as straw, corn stalk, sunflower stalk, remains from cutting vine and olives, seeds from cheeries and apple peel, remains from cattle breeding, and communal and industrial waste. In Republic of Srpska, the potential of biomass for power production, especially thermal energy production, is mostly neglected. The RS Energy Sector Development Strategy by 2030 does not sufficiently analyse biomass as a renewable energy source.

\section{GEOTHERMAL ENERGY}

Geothermal energy implies one of the forms of renewable energy based on thermal energy accumulated in fluids and rock masses in the Earth's crust. It is directly connected with the heat inside our planet, which is transferred to the topographic surface and subsurface parts through a very complex geological structure. Considering the geothermal gradient, the rate of temperature increase with respect to depth increase in the Earth's interior, which is on average about $3^{\circ} \mathrm{C}$ at every 100 metres, we can conclude that it is only the Earth's crust that is important for geothermal energy utilisation. One of the reasons lies in the fact that there is no technical possibility of access to great depths.

\section{GEOTHERMAL RESOURCES}

Basically, geothermal resources are reservoirs inside Earth from which heat energy can be economically separated and used for electricity production or another purpose. Assessments of geothermal resources are carried out upon a number of parameters, such as: the depth, thickness and distribution of geothermal aquifers, rock mass characteristics etc.Regarding the use of geothermal resources in Republic of Srpska, and given that after 1992 no deep geothermal drilling has taken place whatsoever (with the exception of Semberija region in 2010), it can be concluded that low-temperature hydrothermal resources (up to $75^{\circ} \mathrm{C}$ ) are mostly used. In fact, an earlier investigation, as well as the recent one (in 2010), show that all previous investigations confirm the geographical region of Semberija as a resource for the use of geothermal waters, and also that the water temperature (up to $76^{\circ} \mathrm{C}$ ) enables a multifunctional use of these waters [1]. On the current level of analysis (December 2014), hydrothermal resources in Republic of Srpska are

\footnotetext{
3 The RS Integrated Water Management Strategy by 2024, the RS Ministry of Agriculture, Forestry and Water Management, Bijeljina, 2012.
} 
used for fish farming, balneology, recreation, soil heating, cattle breeding, indoor heating etc.

\section{CONCLUSION}

Based on the previous investigation of Republic of Srpska geospace, it can be concluded that renewable energy sources, geothermal resources in particular, have not yet been sufficiently investigated. Future areas of a more intense investigation of lower and medium-enthalpy hydrothermal resources in Republic of Srpska are actually the localities of spas. The region of Semberija represents a very perspective area since it is the most investigated one. The overall depth of previous drill holes in Semberija is about $10.5 \mathrm{kms}$, while water temperatures range even up to $76^{\circ} \mathrm{C}$. Other significant areas are: thermal and thermal and mineral waters of Banja Luka region, (Slatina, Laktaši and Gornji Šeher), Brčansko-šamaška Posavina, Petrovo area (Sočkovac), thermal waters of Višegrad and Lješljani, thermal and mineral waters of Teslić (Banja Vrućica, Vlajići and Čečava) and Kulaši thermal waters. It should be noted that the RS geospace includes a number of localities with the occurrence of thermal waters, but so far they have not been the object of professional or scientific investigation. Some of these waters are thermal waters in natural environment (water temperature over $20^{\circ} \mathrm{C}$, while some of them indicate a possible existence of thermal waters of appropriate temperature).

\section{REFERENCES}

[1] RS Ministry of Industry, Energy and Mining, RS Institute for Geological Research: Geothermal Atlas of Republic of Srpska, Zvornik, 2012

[2] Crnogorac, Č., Spahić, M., Basics of Geoecology, ARTPRINT, Banja Luka, 2012

[3] The Strategy of RS Energy Sector Development by 2030, RS Ministry of Agriculture, Forestry and Water Management, Banja Luka, 2012

[4] The Strategy of Integrated Water Management in Republic of Srpska by 2024, RS Ministry of Agriculture, Forestry and Water Management, Bijeljina, 2012 